Kerryn Dixon, Lorayne Excell, Vivien Linington, Corin Mathews, Manono Mduli \& Geeta Motilal

\title{
Strengthening foundation phase teacher education through mentoring
}

\begin{abstract}
This paper explores a multidimensional mentorship model implemented between lecturers from the foundation phase at the Wits School of Education and four master's students from the University of Limpopo, as part of the Departments of Education's research initiative to strengthen foundation phase teacher education. Using three critical incidents, we interrogate mentors' experiences of their mentoring practices. Two sets of literature, mentoring and social capital are used as a lens for analysing these incidents. Initial findings suggest the relationship has moved from the initiation to cultivation stage (Kram, 1985; Ragins \& Kram, 2007). But, cultural preconceptions, implicit assumptions and institutional practices can impede or enhance information flows and trust. It is argued that weak ties characterised by mentors' heterogeneity is a strength that has resulted in growing professional development. Through a process of reflection-on-practice, we have begun to think of ourselves as a fledging community of practice. This opens up possibilities for the larger research project.
\end{abstract}

Keywords: foundation phase (FP); mentoring; social capital; critical incidents.

Kerryn Dixon, Lorayne Excell, Vivien Linington, Corin Mathews, Manono Mduli and Geeta Motilal, University of Witwatersrand.E-mail: Kerryn.dixon@wits.ac.za, Lorayne.excell@ wits.ac.za, Vivien.linington@wits.ac.za, Corin.mathews@wits.ac.za, Manono.mdluli@ wits.ac.za and Geeta.motilal@wits.ac.za.

South African Journal of Childhood Education | 2012 2(1): 33-49 | ISSN: 2223-7674 | ๑ UJ
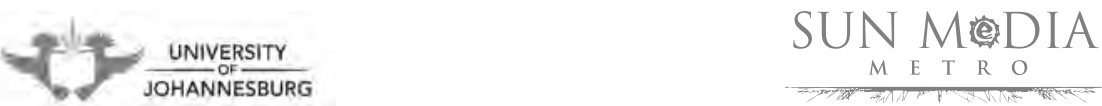


\section{Introduction}

In South Africa primary education is in crisis (Fleisch, 2008). One of the crisis areas is teaching and learning in the foundation phase (FP) which, as the name implies, sets the foundations for learning. There is a critical shortage of FP teachers as well as suitable opportunities to appropriately train them (DBE \& DHE, 2010). One of the current responses to this challenge is a government research initiative aimed at strengthening the capacity of the Higher Education System to provide more and better FP teachers. As a consequence, Higher Education Institutions (HEIs) were invited by the Department of Higher Education (DHE) to submit proposals for inclusion in the FP intervention, which is funded by the European Union (EU).

The Wits School of Education (WSoE), which has recognised expertise in the FP phase and a clearly defined approach to FP teacher education, put forward a research proposal focused on the establishment of a FP community of practice (CoP). The proposal acknowledged the wide range of processes, challenges and characteristics involved in the establishment of such a community. As Wenger (1998) asserts, practice that coheres with the notion CoP has three dimensions, namely mutual engagement, joint enterprise and a shared repertoire.

These three dimensions we posit, developed in a community of practice, could strengthen FP teacher education. In short, our overall aim is to establish and develop a FP CoP that will further teacher education in the FP and in so doing increase learning opportunities for all South Africa's young learners.

A first step towards this aim was to set up a partnership with the University of Limpopo (UL) who do not have a FP teacher education programme. The partnership itself has two central foci. The first is to bring together expertise from both universities and collaboratively design a contextually appropriate FP teacher educator programme for the UL. The second, which is an integral part of the first, is a mentorship model whereby four teachers identified by UL come to the WSoE as postgraduate master's students to gain expertise in the FP and subsequently lead the establishment of a FP teacher educator programme at the UL in 2014. It is expected that during their two years at Wits they will acquire the necessary social capital, for example disciplinary knowledge, to enable them to design and implement a contextually appropriate FP teacher educator curriculum.

This paper reflects on the first six months of the mentorship process from the perspective of the WSoE mentorship team. It asks what we as mentors are learning, and have learned from the mentorship process and it explores the relationship between mentoring and social capital in the context of this project. In this paper we are stepping into a dialogic space in which we hope others will join us. We must stress that we do not intend to exclude the voices of the four UL mentees but that this is the first part of the conversation. 


\section{A mentorship process unfolds}

Mentorship, as Ragins \& Kram (2007) note, is a multifaceted and highly complex process. It brings together disparate views and expectations and demands of all involved flexibility, commitment and a reciprocal willingness to learn. The WSoE mentoring team consists of five members, one man and four women with a range of expertise and experience. Various factors influenced the choice of mentors. Some of these related to expressed interest in the overall project, the specific process of mentoring, and expertise related to teacher knowledge of FP practice and curriculum. All team members have had some experience of the mentoring process and were motivated by a commitment to strengthening FP teacher education in South Africa.

The four mentees, two men and two women, arrived after the start of the Wits 2011 academic year. After initial discussions held in collaboration with the UL project members, it was decided that each mentee would focus on a particular FP specialisation, while acquiring a general FP knowledge base. Of the four mentees, only one had had some FP teaching experience. Two others had been high school teachers and the third mentee had some experience in adult education.

The mentees limited involvement in the FP presented a particular challenge. For while FP teaching shares some pedagogical principles with the other phases in the General Education and Training (GET) band, it also has a range of discrete practices. It is these discrete practices that the mentees needed to acquire. To assist them in this and a wealth of other teacher educator related practices, a mentorship plan was drawn up collaboratively between the mentoring team and the mentees.

This plan was informed by a needs analysis that considered all aspects of their life at Wits from office space, computer use, residence, library access, FP staff meetings, WSoE staff seminars, course choices and timely registration for these courses. The reciprocal nature of the mentor-mentee relationship was established from the outset. The mentees were encouraged to shadow the mentors in all aspects of their professional work with students, lecturers in other divisions and each other. They attended lectures and, as their knowledge base grew, did some lecturing to undergraduate BEd students. The mentees were given readings with specific foci relating to disciplinary and pedagogical content knowledge often addressed in the FP. They partnered members of the division on the two pre-service BEd students' three week teaching experiences. Mentees also attended modules of the Grade R training that the WSoE was delivering for the Gauteng Department of Education.

In addition, they assessed BEd students' work to familiarise themselves with quality issues and misconceptions that arise, for example, in the teaching of literacy. Assessments presented an opportunity for some undergraduate FP students whose mother tongue is not English to write their assignments in their first language, because of the mentees' knowledge of the FP students' mother tongue. An additional advantage was the insight mentors gained into student learning. Opportunities, such as this, where mentor and mentee knowledge was brought to bear on a learning issue 
resonates with the kind of mentorship model we have adopted which emphasises the reciprocal nature of learning.

This reciprocity and shared learning emerged during the different variants of meetings that were held weekly between mentors and mentees. Some of these meetings were one-on-one (between individual mentors and their mentee), and others were group-based where mentees and mentors all came together. The mentors also met as a team to reflect on the processes underway.

Members of both teams kept reflective journals, the contents of which often informed the weekly mentoring meetings. Guided self-reflection is an ongoing feature of the mentees' immersion in the FP CoP. At these meetings issues that arose were openly discussed and perspectives from members of both teams brought to bear on the discourse.

During mentor meetings a number of critical incidents were identified. Some of these incidents form the focus of this paper. These incidents often illustrated vastly different perceptions relating to gender, culture, pedagogical issues, for example, teaching techniques, as well as power relations. The data collected from this discourse forms the basis of our data collection and also informs the ongoing development of the mentorship.

\section{Data set and analysis}

From the outset, structures were put in place to gather detailed records of the mentorship process from all perspectives. The mentors developed a guided reflection tool that was used by both mentors and mentees to capture emerging thoughts, both positive and negative, on the evolving project. The reflections recorded provided a discussion base for the weekly mentorship meetings and prompted avid discussion. All discussions, both formal and informal, were recorded in writing. Data also came from lectures, staff meetings, minutes of mentorship sessions and spontaneous interactions. Our data collection, which is ongoing, includes summaries of meetings (both one-on-one and group based mentor-mentees and mentoring team sessions).

It was during the mentors' meetings, while reflecting on the mentor-mentee process, that a number of critical incidents were identified. These critical incidents tell a story and often highlight important pedagogical issues. Analysis of these incidents can identify the significance, especially the emotional significance, of actions and events on people as they carry out tasks. Critical incidents are useful to explain a particular phenomenon and can identify issues that might require further attention and possibly research. As Tripp (1993) notes, reflection on such incidents is an effective way of identifying the various experiences and to come to a better understanding of the events described by them.

Our analysis was guided by three questions, namely, what were the events or circumstances that led to the critical incident? What were the behaviours of the agent that made these events or circumstances a critical incident? What did we learn from the incident? We were also mindful that the interpretation of critical incidents requires empathy, as participants could reveal sensitive information. 
In order to understand these critical incidents that allow us to go beyond a descriptive account, we draw on two sets of literature: research that comes from the field of mentoring and theory on social capital.

\section{Literature on mentoring}

Traditionally, mentoring has been defined as an intense, dyadic relationship in which a more senior, experienced person, called a mentor, provides support and assistance to a more junior, less experienced colleague, referred to as a protégé or mentee (Hezlett \& Gibson, 2007). Although much of the literature uses the term 'protégés', we prefer to use mentees in the context of this project as our mentees are not protégés in the traditional sense. Our mentoring model is also not a dyadic relationship. Rather, the linearity of traditional models does not suit the context of this project. We have an alternative model of mentoring. This model is multidimensional. It is depicted diagrammatically in Figure 1 below. It represents shared thinking and feedback across three stakeholder groups: the universities, the mentors and the mentees. The model also works from the individual to the group and the group to the individual. There are two sets of mentors for mentees, one at Wits and one at UL. Mentees have their own Wits mentor, but also work with the other Wits mentors who have specialised expertise. Wits mentors collaborate with each other on the mentoring programme.

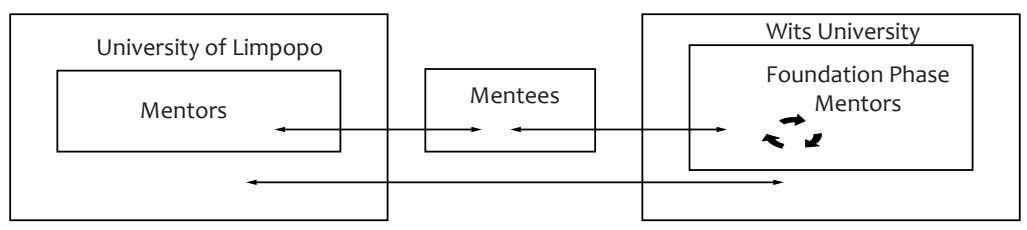

Figure 1: A multidimensional mentoring model.

A core feature of mentoring is that it is a developmental relationship embedded within the career context (Ragins \& Kram, 2007). The primary focus is on career development and growth. Career functions involve coaching mentees, sponsoring their advancements, increasing their positive exposure and visibility, and offering protection and challenging assignments. In our case, mentoring involves the support of mentees in moving from one career to another where they will be required to take on new roles and responsibilities. This cannot be done without building relationships. Mentoring also involves psychosocial functions that build on trust, intimacy and interpersonal bonds. It includes behaviours that enhance and develop the mentees' professional and personal growth, identity, self-worth and self-efficacy.

As a developmental relationship, Kram (1985) has identified four phases of mentoring: initiation, cultivation, separation and redefinition. The initiation phase 
looks at career functions. Our initiation phase was characterised by mentoring sessions that focused on preparing mentees to access FP disciplinary knowledge and plot their trajectory as master's students. The cultivation phase is marked by strong interpersonal bonds and a mutual exchange of ideas and information. This should include a sense of trust and information sharing between mentors and mentees. The separation phase involves a situation where one of the mentors or mentees leaves the organisation or psychologically outgrows the relationship. If the relationship does not disband at the separation phase, it moves into the redefinition phase, which is characterised by psychosocial functions.

There is little research on mentoring from the mentors' perspective particularly in education. But, in dealing with education, Cochran-Smith \& Paris (1995: 183) argue that a mentor's role is defined by a list of activities including orienting the beginner to school and higher education policies, procedures and expectations and providing 'feedback, coaching and support' where interactions should be sensitive, nonjudgmental and supportive. This is a useful starting point. Successful mentors display common attributes. They have an ability to listen, communicate and read people. They have patience and a knowledge of the organisation and industry (Allen \& Poteet, 1999). Mentoring is most effective when it incorporates practical help, such as providing guidance or giving feedback. Good mentors provide regular times to meet, give immediate feedback and are available to mentees (Jones, Reid \& Bevins, 1997). But, Holland (1995) does argue that there are complexities in mentor roles, which may be heightened in the mentor-mentee relationships in teacher education.

Research suggests that mentoring brings a sense of meaning and purpose to mentors, for example, the mentee can be a catalyst for the mentor's professional development (Huling \& Resta, 2001) and stimulate self-reflection (Peterson, 2006). While this may be so, Eby (2007) notes that little research exists on the actual and anticipated benefits of mentoring for mentors. Allen (2007) proposes that work needs to be done to chart the outcomes of high quality mentoring relationships, especially from the mentor's perspective. This project aims to document just this.

\section{Social capital theory}

While there is a large body of work on mentoring, this project does not fit into a traditional model as outlined above. The complex nature of this project involves international, national, provincial and local stakeholders, and we have for this reason applied an alternative mentorship model. But, this model is still institutionally located and it was felt that a broader perspective that accounts for the current issues facing FP education in South Africa was needed. So we turned to the theory of social capital as a way of beginning to understand the processes we are experiencing as mentors.

Capital can be expressed in different ways; it can be financial, physical, human, natural or social (Mubangizi, 2003). Mubangizi (2003) argues that without social capital community goals could not be met even if other forms of capital are present. For the purposes of this paper, we draw attention to the word 'capital' in the concept 
social capital. It implies the notion of possession of resources, but resources that can be circulated within a group. When resources circulate people benefit but not all may benefit equally or at the same time. A good capital investment implies a growth of resources and collective benefits for a group.

Social capital has been defined in various ways and its definitions are not consistent (Storberg, 2002). We work with Coleman's (1988) approach in this paper. Coleman (1988) defines social capital by its function, which comprises aspects of social structures and the actions of actors in the structure. In our case social ties (see below for an explanation) are formed through the mentoring programme, a social structure, and mentors and mentees are the actors within it. For Coleman (1988) social capital is productive and linked to human capital. Human capital brings changes to people by imbuing them with skills and capabilities that make them act in a particular way (Coleman, 1988). This explanation resonates with our project, the aim of which is to develop these skills and capabilities within each other.

In tertiary institutions knowledge production is fundamental. But, early childhood education is under-researched in South Africa, thus building a knowledge base is critical. Kessels and Poell (2004) contend that social capital assists knowledge creation and sharing. These are essential contributors to developing networks and collaboration. In line with Lin (2001), we argue that social capital is an investment in social ties in order to access resources of those in a group is a way of developing knowledge in our field.

Coleman (1988) discusses three features of social capital in the creation of human capital: obligations; expectations and trustworthiness of structures; information channels, norms, and effective sanctions. In the mentoring process we have a set of expectations and obligations to each other. For example, the expectation on the part of the whole group is that a mentoring session will take place. Mentors are obliged to run mentoring sessions. At times, when needed, a mentor with a special area of expertise will run a mentoring session. Another mentor with different expertise will be obliged to repay this 'favour' at another time. In doing things for each other, and in collaboration with each other, a trustworthiness in the social environment begins to grow and an unsaid commitment to repaying the obligation is practised.

The concept of trust is core to literature on social capital. Hezlett and Gibson (2007) discuss five aspects of trust. The first is that cooperative behaviour is related to levels of trust. Secondly, cooperation and trust are reciprocal. Thirdly, trust can be multidimensional, in other words it can be fragile, resilient, or generalised. Fragile trust refers to actors who expose their vulnerability in daily interactions. For example, in a mentor-mentee meeting a mentor admitted to sometimes feeling overwhelmed by research deadlines. In contrast, resilient trust is underpinned by the fact that both parties will not always benefit from the relationship, or benefit equally, but there is an acknowledgement that there will be some benefit. Mentees receive the benefit of knowledge and experience from experts in the field. This benefit, as the mentees noted, has shifted as our relationship with each other has grown and changed over 
time. As mentors, it could be argued that in publishing this paper a different kind of benefit accrues to us. Generalised trust can occur when individuals adhere to norms and behaviours of a larger group although they may not have much direct contact with each other. The three individuals involved in the mentoring process knew each other, but had not worked together collaboratively until this project. There was a generalised trust from their knowledge of each other at the university that working together would be possible.

Social capital is characterised by social ties. These have been described as strong ties, like the ties friends have with each other, or homogenous groups. They are also known as bonding social capital (Helliwell \& Putnam, 2004). Social ties can also be weak, or in the words of Helliwell and Putnam (2004), bridging social capital where groups with little in common work together. These are characterised by heterogeneity. Strong ties appear to build trust whereas weak ties can be fragile. But weak ties extend networks, and use diversity as a resource. Finally, strong ties are not a prerequisite to developing trust. This project is characterised by weak ties. Distance and history mean that the two universities have traditionally had weak ties. In now working together networks are being extended to the mutual benefit of both universities.

The exchange of information is fundamental to social capital and is a means through which action can be taken (Coleman, 1988). One of the ways in which people acquire information is through social interactions. In relationships where there are weak ties, information can be provided from a variety of perspectives. When FP practitioners at all levels are expected to be generalists this is beneficial. The level of institutional, academic, disciplinary and professional knowledge that the mentees require cannot be supported by one mentor. In order to address this, the model provides mentees access to many mentors to deepen their knowledge.

Norms are forms of social capital and can facilitate action or constrain it. Coleman (1988: 104) adds a nuance by stating,

A prescriptive norm within a collectivity that constitutes an especially important form of social capital is the norm that one should forgo self-interest and act in the interest of the collectivity.

Thus an individual may not benefit directly when they adhere to a set of norms, but the collective benefits. But norms and sanctions are often implicit, invisible and entrenched in institutional practices. Newcomers, as is the case of our mentees, enter a space in which the rules and expectations of a university are both different and similar to their schools as workplaces.

Much of the work on social capital and mentoring align with each other and it is to this point that we now turn.

\section{Social capital and mentoring research}

Hezlett and Gibson (2007) argue that most of the work in social capital and mentoring has developed in parallel. Only recently has there been a move to bring the two traditions together. In their review of the research they posit that there is a reciprocal 
relationship between social capital and mentoring where concepts of social capital enrich mentoring and vice versa. Thus, in the next part of the paper we draw together the stages of mentoring, roles of the mentor and Coleman's (1988) theory of social capital as a way of analysing the dynamic relationship between this group of mentors and mentees. We argue that bringing social capital together with mentorship is also the start of understanding larger social networks of which we are a part, and an initial step in considering the ways in which a community of practice may evolve.

The issue of trust emerges in both bodies of literature. But, social capital sees trust from a structural perspective rather than being located in a psychosocial relationship. This broader and slightly more nuanced understanding of trust provides us with a more complex analytic tool with which to assess issues of trust, collaboration and knowledge-sharing as mentors. Since there is little literature on multiple mentors (Hezlett \& Gibson, 2007), the concept of weak and strong social ties from social capital, provides a means of exploring this more complex mentoring model.

Good communication and feedback characterise a successful mentoring relationship. But what is largely absent in the literature, is the content of this information and the information flows. This is unsurprising when mentoring relationships in corporations are often between individuals who already have knowledge of the field. But, what characterises this mentoring relationship is the dissemination of disciplinary knowledge, practical knowledge, pedagogical content knowledge and institutional knowledge of tertiary teacher education. Social capital's framing of information exchange illuminates this fundamental part of the mentoring relationship.

\section{Initial findings from a mentor perspective: three critical incidents}

We now present three critical incidents that we hope provide insight into the role and lessons gained from the perspective of the mentors. These are presented as reflective narratives.

\section{Critical incident one: Asked to leave}

It was Thursday morning, my mentee and I had planned a numeracy lecture together which he was now going to present. I went with him to the lecture room and explained the plan for the day to the students. Immediately thereafter, my mentee asked me to leave the lecture room. This sudden request for me to leave left me wondering why, more so because the request was verbalised in Sepedi. (Sepela, o ye offising ya gago. Nna ke lokile. Rona re lokile. Loosely translated, he said, "Go to your office. I am fine. The students and I are fine.") I did not know how to respond in front of everybody, because I did not want to appear disrespectful to my mentee so I left.

As I left the lecture room - and subsequently - reflected on what happened I realised how uncomfortable this incident made me. I was left with many unanswered questions and still seek answers to the following: Did he ask me to leave because he did not understand my reasons for asking him to do this lecture? Was he perhaps suspicious of my intent? Was this fuelled by a lack of explicit communication on my part? Is everything as clear to him as it is to me 
or is my understanding of the role of the mentor, my perspective on what he should assume, in fact 'clouding', unintentionally, understanding?

Was there a culturally-based element impacting our relationship, I also asked myself. I am a middle-aged African woman mentoring a young African man. I am also a woman from a different province with different cultural belief systems and expectations. These different cultural and belief systems could, I concluded, generate previously unarticulated complexities in the mentoring process. For instance, in some African communities, mostly in deep rural areas, men are viewed as superior to women. As a woman from the city, mentoring a 'rural' man I have often had to think carefully about what I do or say to my male mentee. This male mentee may also expect me to behave in a particular manner as an African woman.

Had I failed, I asked myself, to make the implicit explicit? Should I, from the outset, deliberately have delved, and negotiated, a way through this complex, highly sensitive, culturally-based feature of our relationship? Or had I been assuming that professionalism would, in both our minds, place cultural issues on a different trajectory? Was this naïve? What is the relationship between culture and professionalism? Reflection brought all these issues to the fore.

My aim in asking my mentee to present the numeracy lecture was for him to get an opportunity to present a lecture and interact with students in order to sharpen his FP numeracy content knowledge and presentation skills. I had spent some time with him beforehand where we had discussed the lecture and I had given him the lecture notes and handouts. We had agreed on the time and date for the lecture.

Furthermore, the lecturing approach I had modelled was cooperative, collaborative and highly inclusive. Yet, it had spawned exclusion. Why? My expectation was that the mentee would follow the lecture/review approach that I had been modelling for a number of weeks. In this approach I would lecture while he observed and then, after the lecture, we would review collaboratively what had taken place and how the pedagogical content knowledge had been mediated. I therefore expected that when my mentee presented a lecture it would follow a similar approach. But I didn't make my expectation explicit and that, on reflection, may have been a mistake. Perhaps it led to the mentee's unexpected request for me to leave.

In short, my expectation, as a mentor, was that the model of shared review that I had followed would be equally applicable when we switched roles and he was the lecturer and I the observer. Furthermore, what role, if any, had trust, or lack thereof, played in the creation of this critical incident? Had the level of trust in our mentoring relationship not developed to the level where the mentee could open himself up to possible critique? Would my presence and our joint review expose an area of vulnerability that he was not yet ready to reveal?

In short, I had obeyed his command. As mentor, I had not wanted to cause a scene and challenge the mentee in a public space as there are institutional norms that govern behaviour in the classroom and relationships in the project. And these norms present boundaries within which I operate. But was there also another factor, I pondered. Was culture and my embedded knowledge of its power a central factor in my departure? Which norms take precedence? Institutional? Cultural? And is one always aware of the unspoken power of norms that may at one stage have been woven into your identity?

As a team, we turned to social capital theory as a way of trying to understand the processes we are undergoing as mentors and, in relation to this critical incident, why $M$ had been asked to leave.

Norms are forms of social capital and can facilitate action or constrain it (Coleman, 1988). In the case of M's critical incident, institutional norms and expectations 
appeared to be diametrically opposed to those held by the mentee. But, as we noted earlier, norms and sanctions are often implicit, invisible and entrenched in institutional practices. Newcomers, as is the case of our mentees, enter Wits which has its own rules and expectations. The necessity of negotiation and explicit articulation of the embedded norms of the mentoring programme which are shaped by invisible institutional norms is obviously key.

M's deference to her mentee's request to 'leave' raised issues in her mind about culturally-based power relations. Her reflection on this illustrates the tension that can arise as institutional and cultural norms jostle for precedence. They also potentially open a space for negotiation that in itself can further understanding of the multifaceted and complex nature of the mentor-mentee relationship.

As the mentoring process continues, the weak ties to which we have referred will, we anticipate, provide rich learning opportunities for all parties. Weak ties are often related to heterogeneity, and the heterogeneity of the mentor team is an undoubted strength that is able to deepen insight and broaden understanding. As the mentor team collaboratively reflected on M's being 'asked to leave', differing interpretations arose that stimulated discussion and debate. A number of members of the team realised that their cultural frames were not only shaping their interpretation, but impacting on their immediate ability to 'read' the incident through the eyes of $M$.

As a mentor team we are trying to construct mentoring as collaboration. The collaborative, reflective relationship $M$ has established with her mentee was jolted as it became apparent that her expectations and his were mismatched. $M$ acknowledges in her reflection that she had not anticipated this mismatch and that if she had made her expectations explicit at the outset the critical incident may not have occurred.

As Coleman (1988) asserts, social capital is linked to human capital, which brings changes to people by imbuing them with skills and capabilities that make them act in a particular way. In the 'asked to leave' critical incident, the aim of the mentor was to enhance human capital. The emotions and confusion she encountered through the action taken by the mentee made her question her ability to generate human and social capital in others. And her ability in this regard, and confidence in this ability is, we argue, a process of growth.

Another aspect of social capital is trust (Coleman, 1988) and M's reflection clearly identifies issues relating to this theoretical construct. This incident reveals the operation of fragile trust (Hezlett \& Gibson, 2007). In M's critical incident, she had made an assumption that there was an element of trust between her and her mentee, because they had been in the mentoring relationship for almost three months. She assumed that the mentee would trust her enough to be able to present a lecture in her presence, and that the fragile trust that existed between them would permit him to expose himself to situations that might unsettle him and make him appear vulnerable, e.g. a student asking a question for which he did not currently have the knowledge base. This 'risk taking', she assumed, would not be difficult for him because of the fragile trust that existed between them. But was that fragile trust, in fact, in place? 
Cooperative behaviour is related to levels of trust. In this critical incident, M's shock and confusion on being asked to leave could be linked to the expectations she had, and assumptions she had made that her mentee would be sufficiently cooperative and possess enough trust to follow the lecture/review model she had presented to him as the norm.

Finally, the critical incident raised questions around the establishment of trust and that it cannot be assumed to be in place or developed within a short space of time. It also raises questions about the cultural frames we operate in and that institutional and cultural norms may often be in tension with each other, which can lead to misunderstandings and misinterpretations of events that impact on developing collaborative relationships. It also points to broader relationships between schools and universities about what it means to teach FP.

\section{Critical incident two: Dare to ask}

A discussion between two mentors and two mentees at a weekly mentorship meeting was the context for this incident. Prior to this discussion during a master's session, one of the mentors had presented a conceptual paper that she had co-authored, and which looked among other things at the link between play and emergent literacy. During the mentorship discussion, one mentee queried why no concrete examples of play had been given in the paper. This opened a space to explore the notion of play from a cultural perspective. The mentees pointed out that in rural Limpopo girls had few opportunities to develop gross motor skills in the context of outdoor play, as they were not expected to climb on jungle gyms and other large outdoor equipment. Rather, they would be inside engaging in more sedate activities where the emphasis is on fine motor skill development, activities such as 'diketo' (a numeracy game which involves addition and subtraction), weaving mats and threading beads. The boys, however, were expected to partake in active outdoor play and not focus on the more sedate indoor activities. Suitable activities for boys include playing with wire cars, climbing trees and soccer. It is considered demeaning for boys to participate in girl's activities, and if girls play boys' games it is viewed with disdain. These observations offered by the mentees led to a rich discussion about cultural norms in the relation to play and the role of play in early learning.

This incident, we argue, resonates with many of the constructs depicted in social capital and mentoring literature. The mentorship relationship follows distinct phases (Ragins \& Kram, 2007). We would argue that this critical incident suggests a shift in the relationship from initiation to cultivation, whereas the first incident is located in the initiation phase. The discussion that emanated from this initial question led to a mutual exchange of ideas and information. The evidence of mutual exchange and reciprocity in mentoring sessions is accentuated when both mentors and mentees together identify, read and critically discuss articles relating to disciplinary knowledge. By 'daring to ask', mentees demonstrated that a strong interpersonal bond was beginning to develop, which was based on a sense of trust.

As Ragins \& Kram (2007) note, trust is an important psychosocial component that frames the mentoring process. Trust is characterised by increasingly positive interpersonal relationships between mentor and mentee. And this indeed proved 
to be the case. Over time a congenial atmosphere has developed between the two mentees and mentors. This has deepened into what Hezlett and Gibson (2007) identify as a reciprocal relationship of cooperation and trust. It was, in part, this growing relationship, we suggest, that allowed the mentee to critique the paper and the mentor to open a dialogical space for further debate. Is this evidence of the mentees' increasing professional and personal growth? And has this growth been aided by the mentors whose role is to provide support in a sensitive, non-judgmental environment?

This emotionally safe space facilitated the sharing and exchange of information relating to different culturally contextual practices: in this case how children play and different cultural expectations of their play. The mentees felt confident enough to share disparate understandings of play informed by their cultural contexts. As the team began to explore differences we also began to tease out similarities. This exchange of information by both mentors and mentees enabled the mentors to reexamine their understandings of play from culturally diverse contexts. The mentors come from a context that views children as being embedded in a dominant western European culture. For the mentors this exchange of information was an illuminatory insight. And for the mentees, we suggest, this empowered them to draw from their rich knowledge base and the power relations were reversed as they were placed in a position of strength. They were also 'the experts'.

Social interactions of this nature provide a platform for deepening information exchange, which is a fundamental tenant of social capital (Coleman 1988). The weak ties that characterise this project further enabled a two-way flow of information. The two mentors bring disciplinary and professional knowledge to the relationship and the mentees a knowledge of culture and context that opened space for critique and exploration.

In short, this critical incident shows how specific social interactions enable disparate groups of people to share differing information, which often draws on specific cultural understandings. The ongoing development of trust, which is characterised by weak ties, has enabled the mentees to shift their positions from one of initiation to cultivation.

\section{Critical incident 3: What did you expect?}

All the mentors came together at the beginning of the second semester to 'touch base' and think about the format mentoring sessions might take as the mentees began their academic course work. This would bring about another dimension to the mentoring relationship. The academic demands of course work would require a different approach to how we mentored. In the process we began to talk about our expectations of the mentees in other aspects of our work with them. At this time of the year we are under pressure to have all midyear marks posted. It emerged that some marking had been given to mentees and not all of it had been returned. Questions were then raised about the mentees' role and function in the division: they are colleagues and at the same time not, they are postgraduate students but not bursars paid to work within the division, marking or teaching are valuable learning experiences to begin to 
lecture and assess, but this is not a formal part of 'training'. This discussion came to define the rules of engagement.

We realised that we had never set out what our explicit expectations were at the beginning of the mentoring process. It was such an obvious oversight. If students did not know the institutional practices, in this case around marking, because we had never told them they could not be expected to know how this put us under pressure. Rather than leave this unsaid, we decided that talking about expectations needed to be done. It was decided the mentor who is the Division Head would meet with the mentees. In this meeting the past six months could be reflected on, and goals set for the coming months, as well as a discussion about both groups' sets of expectations that had or had not been met, and what the expectations would be going forward.

In analysing the 'what did you expect?' critical incident, Coleman's (1988) three concepts of social capital emerge as interconnected. Expectations and trust are built on norms for a group to function. When a group has weak ties and is not part of the same institutional culture, there needs to be an information exchange for these norms to be made explicit. In retrospect, setting out expectations seems an obvious starting point when beginning a new relationship. The question then is why this did not happen. We believe that some of the answer lies in the way in which we thought about the initiation phase of mentorship. Because we had not been involved in a mentorship process like this before, we drew on our institutional social capital around registering students and settling them into accommodation, and their new role. We worked from a 'student orientation' perspective which emphasises logistical aspects. The focus is on students feeling secure in a new environment. But these were not 'normal' students; they are individuals who have a more complex identity. In foregrounding mentee needs, what was backgrounded was the role of mentors in setting up a collaborative relationship. When the focus is on logistics, and not on the nature of human interactions on both sides, we run the risk of not being able to fully develop relationships of trust.

This is where the exchange of information is crucial. In this case the exchange of information is about the joint set of expectations around the work ethic at Wits, what constitutes collegial behaviour, the ways in which the mentoring process takes place and preparation for meetings, time management, self-motivation and accountability. The exchange of information in the mentoring sessions is narrower and focuses on disciplinary and pedagogical knowledge as well as the impact of the psychosocial in the new academic endeavour. Information exchange is the means through which action can be taken. If the exchange of information is faulty then the actions that can be taken are compromised and the efficacy of the mentoring process is undermined.

In building trust, communication has to be explicit. In the absence of setting out explicit expectations, it is not clear what the general and specific obligations are for the group and can lead to misunderstandings. In the same way as we may misread a response because we may not have the appropriate cultural frame, mentoring is also about developing a frame for the group's ways of being and working together collectively. The challenge is to continuously develop a relationship of trust with 
strangers who are new to our environment and set clear boundaries that enhance collaboration rather than inhibit participation.

Thus in the exchange of information, norms are implicit and explicit. In this project we did not make the norms explicit. In revisiting these implicit expectations and making them explicit in the meeting with the mentees, we were lucky that on the whole there was agreement. But, we would argue that norms are not static and can be renegotiated as needs change. For example, the ways in which mentoring will take place in the second half of the year will be slightly different, where it was mutually agreed that there be more focus and support on the academic endeavour.

What this critical incident highlights for us is the value of reflection in unpacking incidents that force us to interrogate our own assumptions, beliefs and practices. This 'obvious' oversight has enabled us to plot the way forward with greater clarity and further define what our roles as mentors are. It is also a reminder of the dynamic relationship between human beings which allows for the development of human resources.

\section{Conclusion}

This paper reflects on the first six months of the mentorship process from the perspective of the WSoE mentorship team. It asks what we as mentors are learning and have learned from the mentorship process and it explores the relationship between mentoring and social capital in the context of this project. As noted in the outset of this paper, we did not follow a traditional mentorship model. Consequently, the mentoring process though disparate, and at times convoluted, brought together a range of views and expectations. This, we argue, became the strength of the mentoring process. It is clearly indicated in critical incident two when a mentee challenged a mentor and opened a pathway for dialogue and debate. It also signals a shift from the initiation phase to the beginning of a cultivation stage of mentoring. As mentors we are eager to see how this shift of position plays out with all the mentors. Mentoring has also brought other learning experiences to bear. Our experiences indicate the emergence of two distinct faces of culture. We have been forced to recognise that when one's own cultural practices and beliefs are deeply embedded one is less aware of how they influence the interpretations of events. This, we argue, could be seen as the weak face of culture. The strong face of culture was clearly illustrated through critical incident two where differing culturally based perceptions of play led to rich reciprocal learning. We surmise that the weak ties between the mentor-mentee team allowed the mentee to speak out. Critical incident one aptly shows what happens when these ties are fragile. The mentor-mentee relationship becomes strained and it requires a sensitive, compassionate and reflective response from the mentor to ensure appropriate ties are established that will encourage risk taking and the appropriate exchange of information. This dichotomy between strength and weakness is also relevant to our own mentor team. The weak ties emanating from the racial, gender and cultural 
diversity in the mentor team added strength to the range of interpretations brought to bear on all three critical incidents which, we argue, was generative.

The challenge for the mentors will be how these weak ties develop in the face of growing collegiality and, which the literature reveals, often leads to the strengthening of ties that could change the group dynamic. Furthermore, we suggest that the nature of the mentorship model we adopted has been a strength that opens space for a collective reflection on our practices. This has enabled us to interrogate some of our own practices which, as critical incident three reveals were found wanting, but also enabled us to make changes to the mentorship process.

Lastly, through this process of reflection-on-practice by the mentorship team we have begun to think of ourselves as a fledging community of practice. This has opened multiple possibilities for taking the larger research project forward.

\section{References}

Allen, T. (2007). Mentoring relationships from the perspective of the mentor. In: B. R. Ragins \& K. Kram (eds.), The handbook of mentoring at work: Theory, research, and practice. Thousand Oaks, CA: Sage, pp. 123-147.

Allen, T. D. \& Poteet, M. L. (1999). Developing effective mentoring relationships: Strategies from the mentor's viewpoint. Career Development Quarterly, 48: 59-73.

Cochran-Smith, M. \& Paris, P. (1995). Mentor and mentoring: Did Homer have it right? In: J. Smyth (ed.), Critical discourses on teacher development. London: Cassell.

Department of Basic Education (DBE) \& Department of Higher Education (DHE). (2010). European Union Primary Education Sector Policy Support Programme [Strengthening Foundation Phase Teacher Education] Higher Education Institute (HEI) workshop meeting: 2 June 2010, Pretoria.

Eby, L. T. (2007). Understanding relational problems in mentoring. In: B.R. Ragins \& K. Kram (eds.), The handbook of mentoring at work: Theory, research, and practice. Thousand Oaks, CA: Sage, pp. 323-344.

Jones, L., Reid, D. \& Bevins, S. (1997). Teachers' perceptions of mentoring in a collaborative model of initial teacher training. Journal of Education for Teaching, 23(3): 253-261.

Coleman, J. (1988). Social capital in the creation of human capital. The American Journal of Sociology, 94: S95-S120.

Fleisch, B. (2008). Primary education in crisis. Cape Town: Juta.

Hezlett, S. \& Gibson, S. (2007). Linking mentoring and social capital: implications for career and organization development. Advances in Developing Human Resources, $9(3): 384-412$.

Huling, L. \& Resta, V. (2001). Teacher mentoring as professional development. ERIC Clearinghouse on Teaching and Teacher Education, Washington DC. 
Kessels, J. \& Poell, R. (2004). Androgogy and social capital theory: the implications for human resource development. Advances in developing Human Resources, 6: 146-157.

Kram, K. (1985). Mentoring at Work: developmental relationships in organisational life. Glenview, IL: Scott Foresman.

Lin, N. (2001). Social capital: A theory of social structure and action. Cambridge: Cambridge University Press.

Mubangizi, B. (2003). Drawing on social capital for community economic development: Insights from a South African rural community. Community Development Journal, 38(2): 140-150.

Helliwell, J. \& Putnam, R. (2004). The social context of well-being. Philosophical Transactions of the Royal Society of Biological Sciences, 359: 1435-1446.

Holland, G. (1995). The effect of mentoring experiences on the retention of AfricanAmerican faculty at four-year colleges and universities. Unpublished doctoral dissertation, Illinois State University, Bloomington-Normal, IL.

Peterson, L. K. (2006). Mentoring as a support mechanism for teaching practice by teachers in Higher Education. Eastern Institute of Technology: Hawke's Bay, New Zealand.

Ragins, B. R. \& Kram, K. (2007). The roots and meaning of mentoring. In: B. R. Ragins \& K. Kram (eds.), The handbook of mentoring at work: Theory, research, and practice. Thousand Oaks, CA: Sage, pp. 3-20.

Storberg, J. (2003). The evolution of capital theory: A critique of a theory of social capital and implications for Human Resource Development (HRD). Human Resource Development Review, 1(4): 468-499.

Tripp, D. (1993). Critical incidents in teaching: Developing professional judgment. London: Routledge.

Wenger, E. (1998). Communities of practice: Learning, meaning and identity. Cambridge: Cambridge University Press.

Welch, O. (1996). An examination of effective mentoring models in the academy. Paper presented at the Annual Meeting of the American Educational Research Association, 8-13 April, New York. 